\title{
The face of pain - A pilot study to validate the measurement of facial pain expression with an improved electromyogram method
}

\author{
Karsten Wolf MD, Thomas Raedler MD, Kai Henke MD, Falk Kiefer MD, Reinhard Mass PhD, \\ Markus Quante MD, Klaus Wiedemann MD
}

K Wolf, T Raedler, K Henke, et al. The face of pain - A pilot study to validate the measurement of facial pain expression with an improved electromyogram method. Pain Res Manage 2005;10(1):15-19.

OBJECTIVE: The purpose of this pilot study was to establish the validity of an improved facial electromyogram (EMG) method for the measurement of facial pain expression.

BACKGROUND: Darwin defined pain in connection with fear as a simultaneous occurrence of eye staring, brow contraction and teeth chattering. Prkachin was the first to use the video-based Facial Action Coding System to measure facial expressions while using four different types of pain triggers, identifying a group of facial muscles around the eyes.

METHOD: The activity of nine facial muscles in 10 healthy male subjects was analyzed. Pain was induced through a laser system with a randomized sequence of different intensities. Muscle activity was measured with a new, highly sensitive and selective facial EMG.

RESULTS: The results indicate two groups of muscles as key for pain expression. These results are in concordance with Darwin's definition. As in Prkachin's findings, one muscle group is assembled around the orbicularis oculi muscle, initiating eye staring. The second group consists of the mentalis and depressor anguli oris muscles, which trigger mouth movements.

CONCLUSIONS: The results demonstrate the validity of the facial EMG method for measuring facial pain expression. Further studies with psychometric measurements, a larger sample size and a female test group should be conducted.

Key Words: EMG; Facial expression of emotions; Laser; Pain

Pain has an important impact on humans and society. It is responsible for more than $80 \%$ of all visits to the doctor (1), which makes pain research a necessity for our health care system.

However, because of its complexity, the investigation of pain is a difficult task (2). Besides the physical aspects, the psychological, emotional and interpersonal aspects of pain also have to be considered. A wide range of literature on these issues is available. An overview of this literature was provided by Williams (3). The emotional aspect of pain is an especially important factor in pain research. As Melzack and Wall (4) showed, discordance between the physical pathology and the experience of pain emerges quite frequently. To investigate the emotional aspect of pain, a closer look at the distinct facial pattern of pain is needed. Facial pattern research poses two main problems.
Le visage de la douleur : Un projet pilote pour valider la mesure de l'expression de la douleur faciale au moyen d'un électromyogramme amélioré

OBJECTIF : Le présent projet pilote visait à établir la validité d'un électromyogramme facial amélioré (ÉFA) pour mesurer l'expression de la douleur faciale.

HISTORIQUE : Darwin a défini la douleur reliée à la peur comme l'occurrence simultanée d'un regard fixe, d'une contraction des sourcils et de claquements de dents. Prkachin fut le premier à utiliser le système de codification des actions faciales sur vidéo pour mesurer les expressions faciales tout en utilisant quatre différents types de déclencheurs de la douleur, et d'ainsi repérer un groupe de muscles faciaux autour des yeux. MÉTHODOLOGIE : Lactivité de neuf muscles faciaux chez dix hommes en santé a été analysée. La douleur a été induite au moyen d'un système laser par une séquence aléatoire d'intensités différentes. L'activité musculaire a été mesurée au moyen d'un nouvel ÉFA facial sélectif à haute sensibilité.

RÉSULTATS : Selon, les résultats, deux groupes musculaires sont essentiels à l'expression de la douleur. Ces résultats concordent avec la définition de Darwin. À l'instar des observations de Prkachin, un groupe musculaire est assemblé autour du muscle orbiculaire, ce qui amorce le regard fixe. Le deuxième groupe se compose du muscle de la houppe du menton et du muscle triangulaire des lèvres, lesquels déclenchent les mouvements de la bouche.

CONCLUSIONS : Les résultats démontrent la validité de l'ÉFA facial pour mesurer l'expression de la douleur faciale. Des études supplémentaires s'imposent, comportant des mesures psychométriques, un plus grand échantillonnage et un groupe expérimental de femmes.

First, it is still questionable whether a distinct facial pattern of pain exists and, if such a pattern could be established, it would prove that pain is one of the basic emotions, meaning that it is independent from universal and cultural influence.

Lungwitz (5) postulated that pain is one of five basic emotions. With the help of electroencephalogram spectral analysis, Machleidt et al $(6,7)$ also identified pain as a basic emotion. Ekman (8-10), on the other hand, postulated that there are six different basic emotions, which are each definable by a specific facial pattern. He names surprise, fear, anger, sadness, happiness and disgust, but excludes pain, as the six basic emotions. All studies regarding the universality of facial pain expression faced methodological difficulties (8-12) until Williams (3) demonstrated in a ground-breaking study that it is very likely that a specific facial expression of pain exists. 
Second, the identification of a distinct facial pattern for pain assumes that humans experience pain independently from all other emotions. Unfortunately, pain has close ties with other emotions $(13,14)$.

- Pain and anxiety: pain contributes to the emergence of anxiety, and anxiety can amplify the experience of pain. Furthermore, there are close links between pain and anxiety at various locations within the neuroaxis (15).

- Pain and fear: Darwin (16) emphasized the mandatory presence of fear during the experience of pain. He described the characteristic facial pattern of pain as eye staring with contracted brows and teeth chattering.

- Pain and aggression: Lungwitz (5) postulated that pain and aggression are inseparable. He defined aggression/pain as one of the five basic emotions.

In determining a facial pattern of pain, there are also two methodological difficulties: the inconsistency of standardized triggers and pain measurement methods.

Prkachin (17) was the first to try to solve the problem of inconsistency of standardized triggers by using four different types of pain stimulation in one study (ie, electric shock, coldness, pressure and muscle ischemia). Using the video-based Facial Action Coding System (FACS) to measure facial expressions, Prkachin found four key distinct facial actions in each of the four pain stimuli. Three of the four facial actions were triggered by specific single facial muscles: brow lowering (Action Unit [AU] 4: corrugator supercilii muscle), lid tightening (AU 7: orbicularis oculi muscle) and nose wrinkling (AU 9: levator labii superioris muscle). The fourth facial action, eye closing (AU 43), is triggered by an interplay between different muscles, including the three muscles listed above. Craig (18) and Craig et al (19) found similar results.

Regarding the issue of standardized pain measurement methods, so far, the most popular method for main measurement is FACS, which measures visible facial muscle activity. When using FACS, a high-intensity of pain is needed to achieve accurate measurable results. This makes it more likely for other emotions (eg, fear) to surface during the testing. Several studies have measured visible facial expression to identify a specific expression of pain $(19,10,14,17)$. However, the results were not homogenous.

So far, no studies identifying the facial expression of pain through the measurement of previsible muscle activity have been performed. A measurement of the entire muscle activity, including the important previsible facial muscle activity, can only be achieved by using a sufficiently sensitive electromyogram (EMG) (20-22). Dimberg $(23,24)$ and Dimberg et al $(25)$ were the first to prove the validity of the use of EMGs in identifying facial expressions by matching EMG data to certain kinds and intensities of emotions. In addition, they showed the existence of so called "rapid facial reactions" (25).

However, all the EMG methods that have been applied so far fail to reach sufficient levels of sensitivity and selectivity. In this context, selectivity means the ability to isolate the facial muscle targeted for measurement. Altogether, the more sensitive the EMG, the less selective it tends to be. For this reason, all previous EMG studies were unable to measure more than two to three facial muscles simultaneously.

However, a new EMG method has become available, offering sensitivity and selectivity at the same time. The new method facilitates the simultaneous measurement of nine facial muscles. The validity of this method was recently established in a study of healthy subjects $(26,27)$ and in a study of schizophrenic patients $(28,29)$.

With the use of this method, it should be possible to detect more subtle states of pain within a standardized setting. Having this ability would demonstrate a noticeable progress for the measurment of pain via facial expressions.

Pain induction was done by an elaborate stimulation system - a commercial thulium yttrium-aluminum-garnet (YAG) laser stimulator that works without temperature or pressure. Our primary hypothesis was that pain is expressed by the same three singular facial muscles that were favoured by Prkachin (17) (ie, the corrugator supercilii, orbicularis oculi and levator labii superioris muscles).

\section{Subjects}

\section{METHOD}

The sample consisted of 10 healthy male subjects. The subjects were in good physical condition, had never suffered from any psychiatric illness, had no family history of psychiatric disturbances and had not received any medications for at least three months. The participants had negative drug screenings for opiates, cannabinoids, cocaine, benzodiazepines and amphetamines.

\section{Induction of pain}

All subjects were tested in an electrically shielded, soundproof chamber with reduced light while sitting in a comfortable chair. Subjects were allowed to adapt to their surroundings in the room for $10 \mathrm{~min}$ before testing. Thereafter, subjects were exposed to laser pulses directed at the back of their left hands. The laser pulses were regulated from outside the room. The subjects could not to recognize the start of the pulses visually or audibly. Seven laser pulses were administered in random sequences with different intensities and in irregular intervals.

First, the subjects had to undergo a sequence of approximately 60 laser pulses to identify the individual pain threshold. Pain threshold intensity (Ip) was determined by three series of stimuli ascending in steps of $30 \mathrm{~mJ}$ from below the sensation threshold to $90 \mathrm{~mJ}$ above the pain threshold, and back down again to below the sensation threshold. Thus, Ip was the average of the six values at which the laser pulse was either first noted as a pinprick-like pain sensation (numeric rating scale $=4$ ) during the ascending series or as no longer painful (less than four on the numeric rating scale) during the descending series. The normal value of the Ip derived from the 10 healthy male volunteers ( 20 to 40 years old) in our laboratory was $300 \pm 90 \mathrm{~mJ}$ (mean value \pm 2 SDs).

After a short break of $5 \mathrm{~min}$, seven laser pulses were administered while the facial muscle activity was measured: $120 \mathrm{~mJ}$, (10 s break), $500 \mathrm{~mJ}$, (15 s break), $200 \mathrm{~mJ}$, ( $7 \mathrm{~s} \mathrm{break}), 750 \mathrm{~mJ}$, (20 s break), $500 \mathrm{~mJ}$, (7 s break), $200 \mathrm{~mJ},(30 \mathrm{~s}$ break) and $750 \mathrm{~mJ}$. The pain thresholds were between $250 \mathrm{~mJ}$ and $350 \mathrm{~mJ}$.

\section{Laser method}

A commercial thulium YAG laser stimulator for clinical applications was used (Neurolaser, wavelength $1960 \mathrm{~nm}$, pulse duration $1 \mathrm{~ms}, 5 \mathrm{~mm}$ diameter; Carl Baasel Lasertech, Germany).

\section{EMG measures}

A modified EMG device (Becker MEDITEC, Germany) was used. It did not have any relevant interference between muscles and allowed a high selectivity, which was able to discriminate 
TABLE 1

Significant muscle activity of the nine facial muscles for the 10 male subjects (Wilcoxon test) in the seven different laser intensities

\begin{tabular}{lccccccc}
\hline Muscles & $\mathbf{1 2 0} \mathbf{~ m J}$ & $\mathbf{5 0 0} \mathbf{~} \mathbf{J}$ & $\mathbf{2 0 0} \mathbf{~} \mathbf{J}$ & $\mathbf{7 5 0} \mathbf{~} \mathbf{J}$ & $\mathbf{5 0 0} \mathbf{~} \mathbf{J}$ & $\mathbf{2 0 0} \mathbf{~} \mathbf{J}$ & $\mathbf{7 5 0} \mathbf{~} \mathbf{J}$ \\
\hline 1 & NS & NS & 0.009 & NS & 0.047 & 0.009 & NS \\
2 & 0.036 & 0.036 & NS & NS & NS & NS & NS \\
3 & NS & NS & NS & 0.037 & NS & NS & NS \\
4 & NS & NS & NS & NS & NS & NS & NS \\
5 & NS & NS & NS & NS & NS & NS & NS \\
6 & NS & NS & NS & NS & NS & NS & NS \\
7 & NS & NS & NS & NS & NS & NS & NS \\
8 & NS & NS & NS & 0.046 & NS & NS & NS \\
9 & NS & NS & NS & NS & NS & NS & NS \\
\hline
\end{tabular}

1 Frontalis medialis; 2 Corrugator supercilii; 3 Orbicularis oculi; 4 Levator labii superioris alaeque nasi; 5 Zygomaticus; 6 Risorius; 7 Platysma; 8 Depressor anguli oris; 9 Mentalis. NS Not significant

\section{TABLE 2}

Number of significant muscle reactions* in the seven different laser intensities

\begin{tabular}{lccccccc}
\hline Muscles & $\mathbf{1 2 0} \mathbf{~} \mathbf{J}$ & $\mathbf{5 0 0} \mathbf{~} \mathbf{J}$ & $\mathbf{2 0 0} \mathbf{~} \mathbf{J}$ & $\mathbf{7 5 0} \mathbf{~} \mathbf{J}$ & $\mathbf{5 0 0} \mathbf{~} \mathbf{J}$ & $\mathbf{2 0 0} \mathbf{~} \mathbf{J}$ & $\mathbf{7 5 0} \mathbf{~} \mathbf{J}$ \\
\hline 1 & 0 & 0 & 0 & 0 & 0 & 0 & 0 \\
2 & 0 & 0 & 0 & 1 & 1 & 3 & 1 \\
3 & 1 & 1 & 1 & 5 & 1 & 0 & 2 \\
4 & 0 & 0 & 0 & 2 & 0 & 0 & 1 \\
5 & 0 & 1 & 0 & 2 & 0 & 0 & 1 \\
6 & 0 & 0 & 0 & 1 & 1 & 0 & 1 \\
7 & 0 & 0 & 0 & 1 & 0 & 0 & 1 \\
8 & 0 & 2 & 0 & 2 & 0 & 0 & 1 \\
9 & 2 & 1 & 0 & 1 & 0 & 1 & 2 \\
\hline
\end{tabular}

*An increase of the mean muscular voltage after the laser shot to a value that is greater than the mean value of the preceding baseline plus 2 SDs. 1 Frontalis medialis; 2 Corrugator supercilii; 3 Orbicularis oculi; 4 Levator labii superioris alaeque nasi; 5 Zygomaticus; 6 Risorius; 7 Platysma; 8 Depressor anguli oris; 9 Mentalis

All statistical analyses were conducted using the Statistical Package for the Social Sciences, version 6.1.1 for Macintosh (SPSS Inc, USA). Baseline-to-trial changes of muscular activity (average mean) were tested with Wilcoxon tests for the whole group. To test the hypotheses, $\mathrm{P}=0.05, \mathrm{P}=0.01$ and $\mathrm{P}=0.001$ were accepted as nominal level of significance, high significance and very high significance, respectively. Hypothesis testing was two-tailed.

miniature surface silver/silver chloride electrode (Marquette Hellige, Germany) (inside diameter $0.6 \mathrm{~cm}$ ) filled with Med-Tek/Synapse conductive electrode cream (Kustomer Kinetics, USA). Electrodes were placed according to the recommendations of Fridlund and Cacioppo (30) with the exception of the electrodes over the platysma, which was placed according to anatomical knowledge.

The interelectrode distance was $12 \mathrm{~mm}$. Skin was prepared by abrasion with $70 \%$ clinical alcohol followed by Hellige Epicont abrasive skin preparation cream. The electrodes were connected to Becker MEDITEC Amplifiers. The raw EMG signal was analyzed automatically by a two-channel, contour-following integrator (Varioport, Becker MEDITEC, Germany) with a frequency range $(-3 \mathrm{~dB})$ of $90 \mathrm{~Hz}$ to $500 \mathrm{~Hz}$ and a time constant of $0.0018 \mathrm{~s}$. The amplification factor was $5000( \pm 2 \%)$, the common mode rejection ratio was $77 \mathrm{~dB}$ at $50 \mathrm{~Hz}$, the time constant of integrator was $0.1 \mathrm{~s}$, the range was $\pm 250 \mu \mathrm{V}$, the resolution of $\mathrm{AD}$-Converter 12 Bit was 4096 steps and the resolution of signal was $0.122 \mu \mathrm{V}$ per step. The input impedence is theoretically $1 \mathrm{G} \Omega$, but due to the cable capacities of the equipment, it was about $500 \mathrm{M} \Omega$ at $50 \mathrm{~Hz}$. The sampling rate was $32 \mathrm{~Hz}$. The output signals were recorded and stored in computer files (Variograph software for Macintosh, Becker MEDITEC, Germany) for off-line analysis. With the help of video recordings, the complete EMG data were screened for artifacts like eye blinking. The artifacts were interpolated with the Variograph software.

\section{Statistical analyses}

For EMG baseline values, the measures obtained during the last $3 \mathrm{~s}$ before a laser pulse were used and the $4 \mathrm{~s}$ after the laser stimulus was used as the trial phase.

Changes of facial muscle activity were calculated as the difference between the average voltage observed during trial and the average voltage observed during baseline. A facial muscle reaction was defined as an increase of the mean muscular voltage after the laser pulse to a value which is greater than the mean value of the preceding baseline plus two baseline SDs.

\section{RESULTS}

Facial muscle activity of the group (Wilcoxon tests)

Table 1 shows the significant muscle activities of the nine muscles during the seven different stimuli. Four of nine muscles showed significant activities: the frontalis medialis at $200 \mathrm{~mJ}$ and $500 \mathrm{~mJ}$; the corrugator supercilii at $120 \mathrm{~mJ}$ and $500 \mathrm{~mJ}$; the orbicularis oculi and depressor anguli oris muscles at $750 \mathrm{~mJ}$. The highest laser pulse intensity of $750 \mathrm{~mJ}$ was the only one to activate more than one muscle.

Facial muscle reaction of single subjects

Table 2 shows the number of significant muscle reactions of the nine facial muscles as a response to different stimulus intensities. The highest activation frequencies are seen during the highest intensity (ie, $750 \mathrm{~mJ}$ ). During the intensity of $120 \mathrm{~mJ}$, which is below the pain threshold, the orbicularis oculi and mentalis muscles were significantly activated.

Figure 1 shows the number of significant muscle reactions throughout the entire experiment, independent of the varying laser intensities (Table 2)

\section{DISCUSSION}

This is the first study that simultaneously measures the previsible activity of the nine most important facial muscles (ie, frontalis medialis, corrugator supercilii, orbicularis oculi, levator labii superioris alaeque nasi, orbicularis oculi, zygomaticus, risorius, platysma, depressor anguli oris and mentalis) in healthy subjects during a well-standardized setting. In contrast to the measurement with video-based FACS (8) or microcomputer-based methods (31-33), our method reached sufficient levels of both sensitivity and selectivity. This minimized the possible measurement of other emotions, thereby allowing for standardized pain measurement methods which are appropriate for experimental settings. The validity of the method was established in a recent 


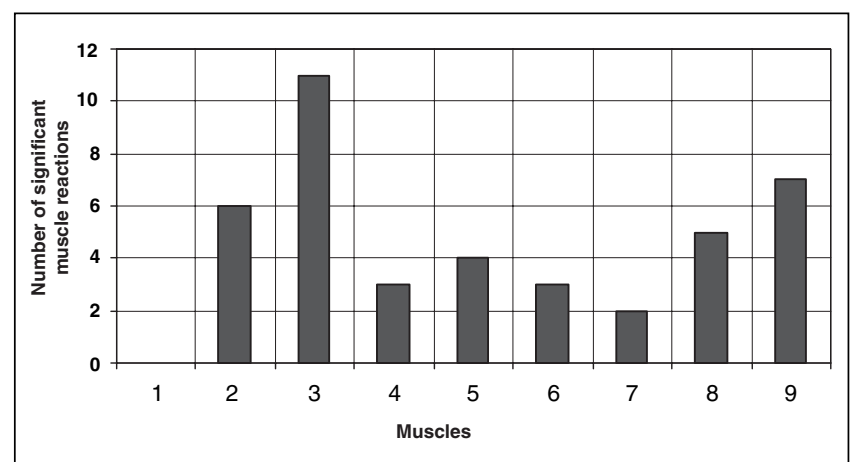

Figure 1) Number of significant muscle reactions (increase of the mean muscular voltage after the laser pulse to a value which is greater than the mean value of the preceding baseline plus two baseline SDs) of the 10 male subjects at all seven different laser intensities. 1 Frontalis medialis; 2 Corrugator supercilii; 3 Orbicularis oculi; 4 Levator labii superioris alaeque nasi; 5 Zygomaticus; 6 Risorius; 7 Platysma; 8 Depressor anguli oris; 9 Mentalis

study of healthy subjects, in which nine facial muscles were measured simultaneously (27). Pain induction was done by a commercial thulium YAG laser stimulator that works without temperature or pressure.

Considering that the present study is a pilot study, designed to test and validate an improved method in pain research, we refrained from applying psychometric methods or other psychophysiological methods.

The present study's major discovery was that the emotional state of pain induced by a laser pulse is mainly expressed through two groups of facial muscles. The first muscle group (primarily, the orbicularis oculi muscle and secondarily, the corrugator supercilii muscle) initiates the facial movement of eye closing or eye staring. This finding is in concordance with Prkachin's (17) results. However, Prkachin did not identify the second muscle group in his experiments. The second group consists of the mentalis and depressor anguli oris muscles, which initiate mouth movements. Our results regarding the involvement of these two muscle groups support Darwin's hypothesis (16).

The facial pattern identified in the present study is distinctively different from other facial patterns identified with our method (ie, joy [27], disgust, appetence [27] and fear [unpublished data]).

Based on our research, it is likely that the facial pattern identified is a pain-specific pattern. However, the present study was conducted with male subjects only, meaning that it did not take into account the possible effects of sex, which have been well documented (34-36). Furthermore, it remains questionable whether the feeling of fear is mixed into the feeling of pain, an occurrence already mentioned in Darwin's hypothesis (16). The fact that the subjects could not calculate the moment of the laser pulse, might, at first glance, implicate the involvement of fear of the laser pulse in addition to the induced pain in the final facial pattern.

On the other hand, none of the fear-specific muscles (ie, risorius, platysma and frontalis medialis muscles $[8,16$, unpublished data]) were identified in the facial expression of pain in the present study, which makes the involvement of fear unlikely.

One important finding is the significant activation of the orbicularis oculi muscle and the mentalis muscle below the pain threshold. This activation below the pain threshold leads to the speculation that it is a preliminary stage of an actual pain expression.

\section{CONCLUSIONS}

Generally, the present pilot study's data demonstrate the validity of this improved facial EMG method in measuring the facial expression of pain.

To draw exact conclusions from the data, the results would need to be validated with different induction designs with additional psychometric measurements and with a larger sample size. The inclusion of female subjects would also be necessary to identify the effects of sex on the pain expression.

\section{REFERENCES}

1. Gatchel R, Turk DC. Psychological Approaches to Pain Management: A Practitioner's Handbook. New York: The Guilford Press, 1996.

2. Chapman CR, Casey KL, Dubner R, Foley KM, Gracely RH, Reading AE. Pain measurement: An overview. Pain 1985;22:1-31.

3. Williams AC. Facial expression of pain: An evolutionary account. Behav Brain Sci 2002;25:439-55.

4. Melzack R, Wall PD. Pain mechanism: A new theory. Science 1965;150:971-83.

5. Lungwitz H. Die Entdeckung der Seele. Berlin: Walter de Gruyter \& Co, 1947.

6. Machleidt W. Grundgefühle: Phänomenologie, Psychodynamik, EEG-Spektralanalytik. Berlin/Heidelberg: Springer, 1989.

7. Machleidt W, Debus S, Wolf K. Die Identifikation von fünf Grundgefühlen durch spektrale EEG-Muster. In: Wunderlich H-P, ed. Angst - Anfall - Aggression. München: ZuckschwerdtVerlag, 1993.

8. Ekman P. Emotion in the Human Face. New York: Cambridge University Press, 1982

9. Ekman P, Friesen WV. The Facial Acting Coding System: A Technique for the Measurement of Facial Movement. Palo Alto: Consulting Psychologists Press, 1978.

10. Ekman P. Facial expression of emotion: New findings, new questions. Psychol Sci 1992;3:34-8.

11. Izard CE. Innate and universal facial expressions: Evidence from developmental and cross-cultural research. Psychol Bull 1994;115:288-99.

12. Russell JA. Is there universal recognition of emotion from facial expression? A review of the cross-cultural studies. Psychol Bull 1994;115:102-41.

13. Kappesser J, Williams AC. Pain and negative emotions in the face: Judgements by health care professionals. Pain 2002;99:197-206.

14. LeResche L, Dworkin SF. Facial expressions of pain and emotions in chronic TMD patients. Pain 1988;35:71-8.

15. Panksepp J. Affective Neuroscience: The Foundations of Human and Animal Emotions. New York: Oxford University Press, 1998.

16. Darwin C. The Expression of Emotions in Man and Animals. New York: Philosophical Library, 1872.

17. Prkachin KM. The consistency of facial expressions of pain: A comparison across modalities. Pain 1992;51:297-306.

18. Craig KD. Ontogenetic and cultural determinants of the expression of pain in man. In: Kosterlitz HW, Terenius LY, eds. Pain and Society. Weinheim: Verlag für Chemie, 1980:39-52.

19. Craig KD, Prkachin KM, Grunau RVE. The facial expression of pain. In: Turk DC, Melzack R, eds. Handbook of Pain Assessment, 2nd edn. New York: Guilford Press, 1992:153-69.

20. Tomkins SS. Affect, Imagery, Conciousness. Vol 1, The Positive Affects. New York: Springer, 1962.

21. Tomkins SS. Affect, Imagery, Conciousness. Vol 2, The Negative Affects. New York: Springer, 1963.

22. Smith RP. Frontalis muscle tension and personality. Psychophysiology 1973;10:311-2.

23. Dimberg U. Facial reactions to facial expressions. Psychophysiology 1982;19:643-7.

24. Dimberg U. Facial electromyography and emotional reactions. Psychophysiology 1990;27:481-94. 
25. Dimberg U, Thunberg M. Rapid facial reactions to emotional facial expressions. Scand J Psychol 1998;39:39-45.

26. Wolf K, Mass R, Kiefer F, Wiedemann K, Naber D. Characterization of the facial expression of emotions in schizophrenia: First results with a new EMG method. Schizophr Res 2005. (In Press)

27. Wolf K, Mass R, Kiefer F, Naber D, Wiedemann K. The facial pattern of disgust, appetence, excited joy and relaxed joy - an improved facial EMG study. Scand J Psychol 2005. (In Press)

28. Wolf K, Mass R, Kiefer F, Wiedemann K, Naber D. The influence of Olanzapine on facial expression of emotions in schizophrenia an improved facial EMG study. Ger J Psychiatry 2004;7:14-9.

29. Wolf K, Mass R, Kiefer F, et al. The influence of olanzapine vs. risperidone on facial expression of emotions in schizophrenia a facial EMG Study. J Clin Psychopharmacol 2005. (In Press)

30. Fridlund AJ, Cacioppo JT. Guidelines for human electromyographic research. Psychophysiology 1986;23:567-89.
31. Katsikitis M, Pilowsky I, Innes JM. The quantification of smiling using a microcomputer-based approach. J Nonverbal Behav 1990;14:3-17.

32. Pilowsky I, Katsikitis M. The classification of facial emotions: A computer-based taxonomic approach. J Affect Disord 1994:30:61-71.

33. Thornton M, Pilowsky I. Facial expressions can be modeled mathematically. Br J Psychiatry 1982;140:61-3.

34. Berkley KJ. Sex differences in pain. Behav Brain Sci 1997;20:371-80.

35. Berkley KJ, Holdcroft A. Sex and gender differences in pain. In: Wall P, Melzack R, eds. Textbook of Pain, 4th edn. New York: Churchill Livingstone, 1999:951-65.

36. Derbyshire SW, Nichols TE, Firestone L, Townsend DW, Jones AK. Gender differences in patterns of cerebral activation during equal experience of painful laser stimulation. J Pain 2002;3:401-11 


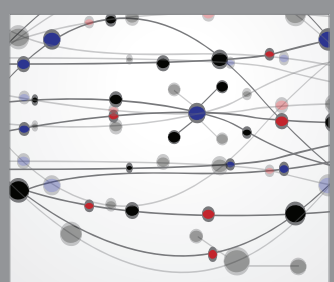

The Scientific World Journal
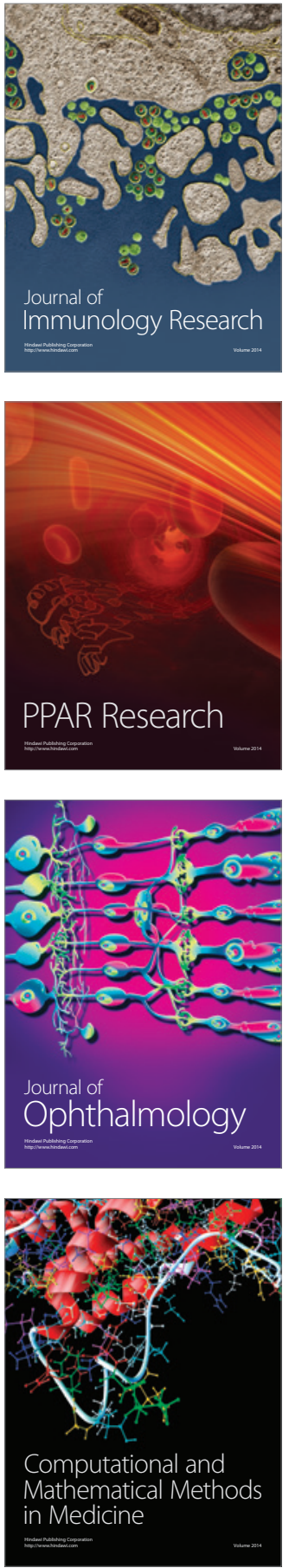

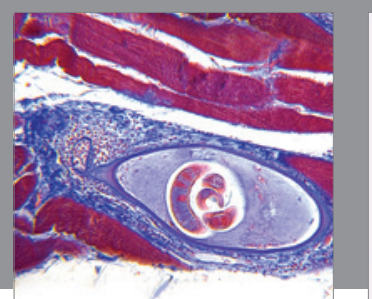

Gastroenterology Research and Practice

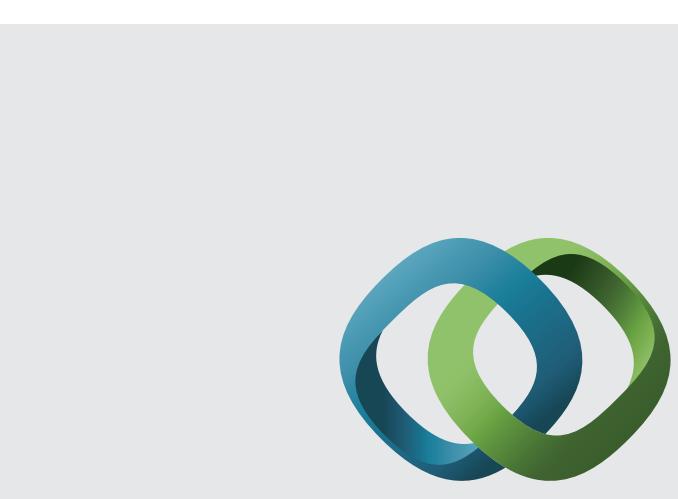

\section{Hindawi}

Submit your manuscripts at

http://www.hindawi.com
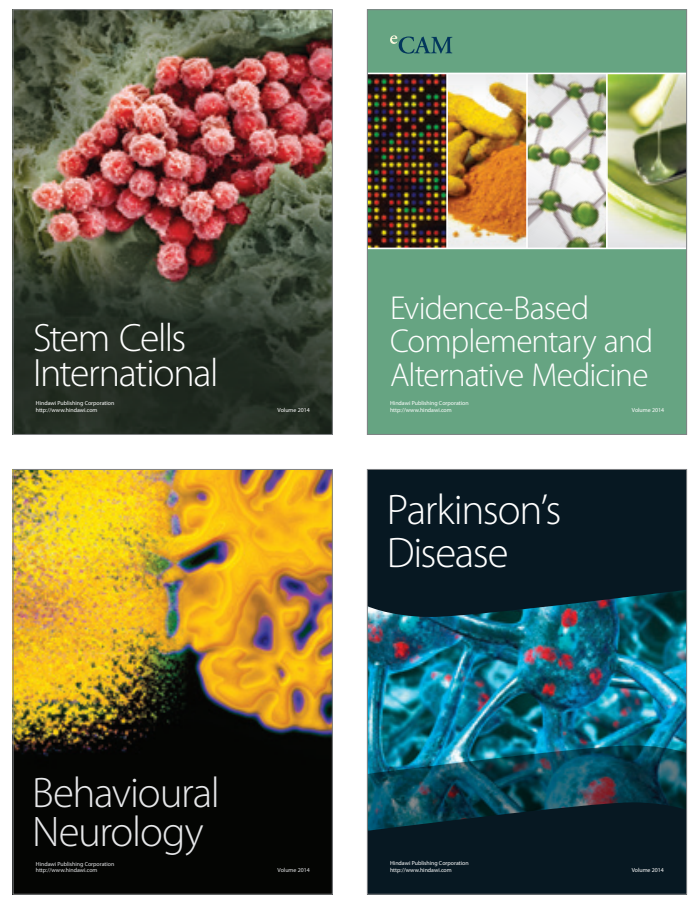
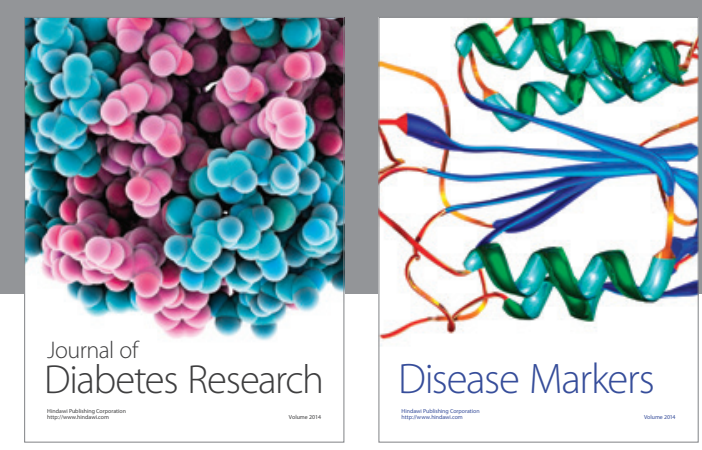

Disease Markers
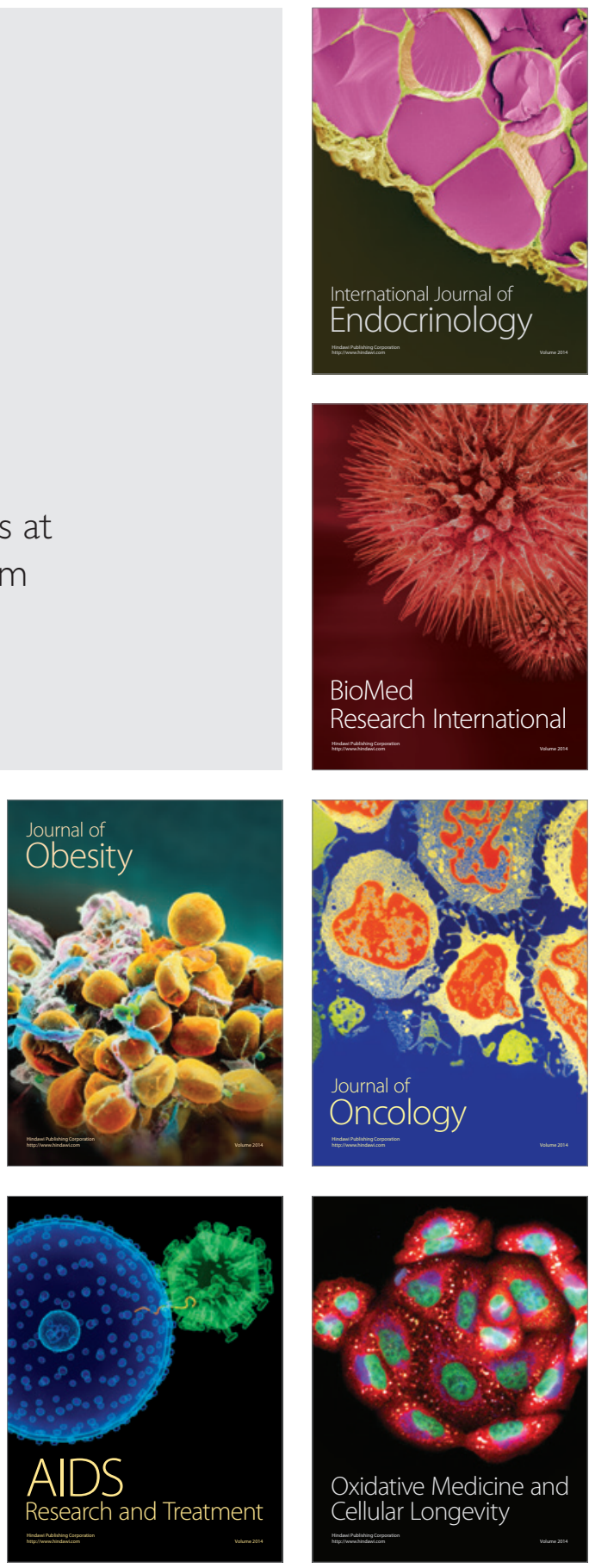